\title{
5 Dementia in Familial Documentary Film
}

\author{
The Ethics of Representation \\ and the Ethics of Care ${ }^{1}$
}

\section{Raquel Medina}

In the past two decades, an increasing number of documentary films have explored the effect of dementia on the person living with it and/or the effect it exerts on those caring for them. Some of these films are directed and narrated by the children or grandchildren of the person living with dementia and focus on difficult ethical issues that result from combining familial care with the documentary practice. If storytelling about and with people living with dementia is a powerful way to highlight issues such as vulnerability and care, this vulnerability can be further increased when filmmakers exert their narrative power with the purpose of both/ either reconstructing a past that is no longer remembered by the people living with dementia and/or narrating their present. People living with dementia are already vulnerable in social settings due to their dementia, but documentary practice can greatly add to their vulnerability.

This chapter examines two documentary films: the Mexican Tiempo suspendido [Time Suspended] (2015) by Natalia Bruschtein and the Spanish El Señor Liberto y los pequeños placeres [Mr Liberto and the Small Pleasures] (2018) by Ana Serret. In Bruschtein's film, the filmmaker interviews her grandmother Laura Bonaparte, who lives with dementia and is well known as one of the co-founders of the movement "Madres de la Plaza de Mayo" in Argentina. In Serret's film, the filmmaker records the daily life of her father Liberto Serret, a retired civil engineer and inventor who has Alzheimer's disease and lives with his daughter, son-inlaw, and grandchildren.

Documentaries about and with people living with dementia such as these two films are powerful tools that raise important issues such as the ethics of representation, vulnerability and care. Hence, how these tools are employed to tell the story of vulnerable subjects has a crucial ethical dimension that affects not only the person with dementia and the viewer but also the way caring for a person with dementia is (re)presented and provided. Amelia DeFalco points out the different meanings of care: "We give care, take care, care for, care about, have cares, and don't care. In its broadest sense, care is affection, devotion, responsibility; even obligation; it is action, behaviour, motivation, and practice: care feels and care 
does" (5). Within these meanings of care, these two films offer different cinematographic (re)presentations of people living with dementia and exemplify two different responses to and notions of "to care for" and "to care about" people with dementia.

\section{Documentary Film: The Ethics of Representation and the Ethics of Care}

Carol Gilligan's feminist concept of care ethics questioned the male model of moral reasoning and decision making. This criticism, Nel Noddings explains, opened an important path to understanding the ethics of care as not only gendered but also relational and interdependent, thus leading to the notion of interpersonal caring relationships. According to Christine M. Koggel, these interpersonal caring relationships are based on a recognition that the individual is part of different networks of relationships at personal, political and social levels, instead of an isolated entity. These two films certainly take different approaches to the ethics of care: while El Señor Liberto emphasises the personal and caring relationship between the filmmaker and the person with dementia, Tiempo suspendido highlights the roles played by the public and private figures of the person with dementia. That is, the purpose of each film is different: whilst Tiempo suspendido is mainly preoccupied with the public figure of Laura Bonaparte and the impact of her memory loss on her country's historical memory, El Señor Liberto is concerned with how the person with dementia continues to live, communicate, and enjoy life. Therefore, I argue that the purpose of the film influences the position of the persons living with dementia on screen, their potential vulnerability to psychological harm, and the cinematographic aesthetics employed.

The documentary mode selected to communicate with the audience shapes the response the viewer might have to the person with dementia on screen and has implications for real-world relations with people living with the condition. In the past few decades, the ethics of documentary film and the ethical responsibilities of filmmakers have been extensively debated. Among the issues at stake, two aspects are of relevance for the present analysis: firstly, consent in situations where filmmaker and subject are personally related and there is a clear intimacy between the two and, secondly, the harm to subjects that the interaction can cause. John Katz and Judith Katz have highlighted that in familial documentaries the intimacy of the family relationship is stressed from the beginning, which in most cases stops the viewers from thinking whether in certain circumstances the filmmaker is pushing ethical boundaries in relation to representation and consent. As G. Thomas Couser suggests for lifewriting, when people with dementia are the protagonists of narratives about them, their cognitive impairment may prevent them from consenting to their representation and from responding to it $(\mathrm{x})$. 
Documentary film endeavours to explore important social and cultural issues. There are two important and divergent approaches to documentaries depending on whether the emphasis is placed on the filmmaker's perspective or the object/film itself and its perception by the viewer. Bill Nichols suggests that documentaries inform or try to influence a viewer's opinion, but most importantly present the filmmaker's perspective on an issue. Distancing himself from Nichols' emphasis on the filmmaker's perspective presented in the film, Garnet Butchart characterises documentary film as a visual representation and a phenomenological perception that deepens "the sphere of the self-transcending gaze of cinematic perception in the presence of which any emergent object acquires identity and is thus made meaningful for a cinematic world" (437). Considering both perspectives, it can be argued that, despite the conscious, initial intentions of the filmmaker, the final product that reaches the audience attains first its own reality and materiality and is then perceived and interpreted by the viewer. Consequently, a film could hold a different meaning from the one originally conceived once it is interpreted.

The materiality and phenomenological nature of documentaries mean that the tools of production and what is presented on screen are equally key elements for both the reception of the film and the meaning that the viewer assigns, in the present case, to the person living with dementia. It is the phenomenological nature of the film that facilitates the encounter between private/personal and public/social dimensions of care: the private interpersonal caring relationship captured on screen ceases to be private (personal) to become public (social). In relation to journalism, Baastian Vanacker and John Breslin stress that Noddings' concept of interpersonal caring relationships, based on the idea that everyone wants to be cared for, is insufficient for addressing how care can be put into practice in the public world (203). They argue that, if the ethics of care is limited to personal relations (private sphere), it is unlikely that it can have practical applications or be a guiding principle in public institutions (203).

The film becomes an independent entity that is interpreted in different ways by different viewers through emotions, feelings and affects. Therefore, it is the new relationship in the public sphere between each viewer and its object of contemplation that may put the person living with dementia in a vulnerable situation. The film is a narrative composed of images and sounds that significantly influence not only the viewer's perception of the caring relationship depicted, but also our broader ideas about dementia, people living with dementia and care for people with dementia. As suggested by Susan Sontag in Regarding the Pain of Others with regards to photography and war, (re)presenting atrocity and violence suffered by others may generate diverse and opposing responses in terms of feelings, emotions and affects: repulsion, shock, pity, sadness, or fascination and attraction. Applying the same principle to people living 
with dementia (re)presented in a documentary film, there may be a wide array of viewer responses.

What is visually narrated in film embodies important notions of care that need to be carefully considered. Consequently, cinematographic language plays a key role in placing the person with dementia in relation to the viewer in certain ways (e.g., as a vulnerable subject or as a resilient one). Returning to the concept of the ethics of care, it is precisely the distance between film and viewer that has important implications for the notion of care, since the viewer cannot provide care for the person on screen. Viewers can respond in any of the ways Sontag suggests but cannot look after the person on screen; they cannot establish a "material" reciprocal caring (inter)action. How, then, could the spectators have a relational or reciprocal caring interaction with the subject-object of their gaze?

Leaving aside the various approaches that the "affective turn" scholars have to the concepts of affect, emotion, and feeling, ${ }^{2}$ it is important to note that images of old age and dementia predominantly have generated emotions of fear, sadness and impatience, as well as feelings of disgust and repulsion. ${ }^{3}$ If we follow Kristyn Gorton's notion that "feeling is negotiated in the public sphere and experienced through the body" (334), we can understand why erasing the traces of ageing from the body through cosmetics or surgery - or from the photographic image of a body - through Photoshop - is so important in a youth-centric society. Hence, gazing at older people living with dementia might cause emotions of fear and feelings of disgust. How can these socially and culturally preestablished and constructed emotional reactions and feelings about older people living with dementia be overcome? How can the moving image of film reverse these responses without erasing older persons living with dementia from the screen?

Affect and affective communication are core to care as relational practice. Teresa Brennan argues that the subject-object binary can be eliminated through affect, which makes possible the ethics of relationality. One affects others and one is affected by others; we "feel with others" (123). Moreover, she claims that in affect sight is no longer deemed to be the most important sense. If with sight the binary of subject (viewer) and object (person who is seen) is sustained, with affect the other senses of the body can interconnect and dissolve the binary. Within film studies, Laura Marks introduces the concept of haptic visuality, a visuality that functions like the sense of touch by activating physical memories of smell, touch and taste. Medina and Zecchi argue that hapticity "is evoked by certain formal strategies to represent the ageing body (extreme close-ups and long duration shots; video imagery; photographs in isolation or combination) and by affective imagery that triggers multi-sensorial experiences (caressing, smelling, hearing, and tasting)" (260). In this way, films that offer this type of multisensory experience work through affectivity to 
produce relationality between those within the film and the viewer and to weaken the object-subject binary.

Judith Butler aims to give answers to some of the ethical questions raised by Sontag in relation to vulnerability and our ethical response to suffering. Butler claims that "the way in which suffering is presented to us, and how that presentation affects our responsiveness" is important (951). How the presentation of suffering is framed can either trigger affective reactions or suppress responsiveness (955). Drawing on Butler's approach, the following comparative analysis illustrates how two radically different cinematographic (re)presentations of people with dementia solicit different affective responses and, in doing so, embody two different responses to and notions of "to care for" and "to care about" them. Furthermore, it argues that Tiempo suspendido and El Señor Liberto present very different modes of thinking about and visualising people with dementia, their personhood, and the ethics of care. Tiempo suspendido is rooted in static binaries: the self/the other, the able/the disabled, before/ now. This results in a film primarily focussed on forgetting as the major sign of dementia (the mind) and on the conceptualisation of the aged body without a mind as embodiment of an archaeological ruin (Dubois). Memory loss is used as a trope to discuss the national forgetting of atrocities committed by the Junta Militar in Argentina (1976-1983), and the need to create a prosthetic memory (Landsberg) that prevents those memories from disappearing. El Señor Liberto presents the perspective of Liberto and his experience living with dementia using the camera in a twofold distinctive mode: as the visualisation of Liberto's subjectivity and as the visualisation of other forms of communication which are paradoxically not visual. That is, while Tiempo suspendido reinforces in both content and form the Cartesian division between body and mind and between able and disabled, El Señor Liberto proposes a way to overcome this duality by portraying the continuum that exists between the self and the other not through reason and cognition but through the embodiment of affect. Finally, employing Teresa Brennan's approaches on affects and the ethics of relationality, this chapter evaluates how El Señor Liberto presents a different visual approach to the ethics of care. It does so by considering the film from a queer perspective and seeing it as a space of encounter in which affect is created by the filmmaker to communicate to and share with the viewer the lived experience of the person with dementia.

\section{Tiempo suspendido}

In Tiempo suspendido, Bruschtein presents a series of personal encounters with her grandmother, Laura Bonaparte. Bonaparte was an Argentinian psychologist and human rights activist whose former husband and three of her children (two sons-in-law and one daughter-in-law) 
disappeared during the Dirty War (1976-1983). In 1985, after having spent nine years exiled in Mexico, Bonaparte returned to Argentina and in 1986 co-founded a new strand of the "Mothers of Plaza de Mayo," an organisation that fought to preserve the memory of the 30,000 "desaparecidos" [the missing] and to bring the perpetrators to justice.

Bruschtein started working on this project in 2011, once her grandmother's Alzheimer's was rapidly progressing and after seeking permission from her uncle, Bonaparte's only surviving son, and cousins before she started filming (Medina, "Interview with Natalia Bruschtein"). When Bruschtein began shooting the film, Bonaparte was not able to recognise her, but nonetheless, some affective connection seemed to remain, because according to Bruschtein, Bonaparte felt at ease and safe with her granddaughter during the shooting of the film (ibid.). Bruschtein states that she was trying "to recover the last thing that remains of a woman I have always admired. I think that it is fair that she is the one who remains in the memory of the viewer" (ibid.).

The documentary was shot over the span of three years in different locations: the nursing home where Bonaparte had lived for the past few years and the family spaces she visited with her granddaughter, including those of Bonaparte's childhood and youth. The progression of Bonaparte's dementia in those years is reinforced by the time constrictions of the film and the structuring of the documentary as a sequence that constantly emphasises chronological contrasts in Bonaparte's life: before the disappearance of her family members; the time of her human rights activism against the atrocities committed in Argentina; and Bonaparte at the time of the narration. The repetition of this pattern generates a strong contrast between the "before" and the "now" of Bonaparte that seems to characterise her present as meaningless. The focus of the camera on her memory loss (made evident by her long silences and vacant stare) and her ageing and wrinkled body bolsters the notion of ageing and dementia as decline and loss of selfhood and presents a nostalgic perception of the past (see Figures 5.1 and 5.2).

The opening extreme close-up shots introducing Bonaparte at the time of the narration concentrate on her grey hair, wrinkled face and shaky, thin hands. The length of the shots pushes the viewer to look at Bonaparte for quite some time, with the camera focussing on her older body and vacant expression. The film soon reveals through an establishing shot that she lives in a nursing home. In clear contrast with this opening sequence, the following sequence shows a jubilant Bonaparte in her nursing home room, talking about having had a very happy childhood. The viewers are placed by the camera in the position of the camera itself, as if they were there with Bonaparte in the room. However, this is still an objective camera with the function of making the spectators sit back, watch and listen to the daily routine of this woman, her encounters with 

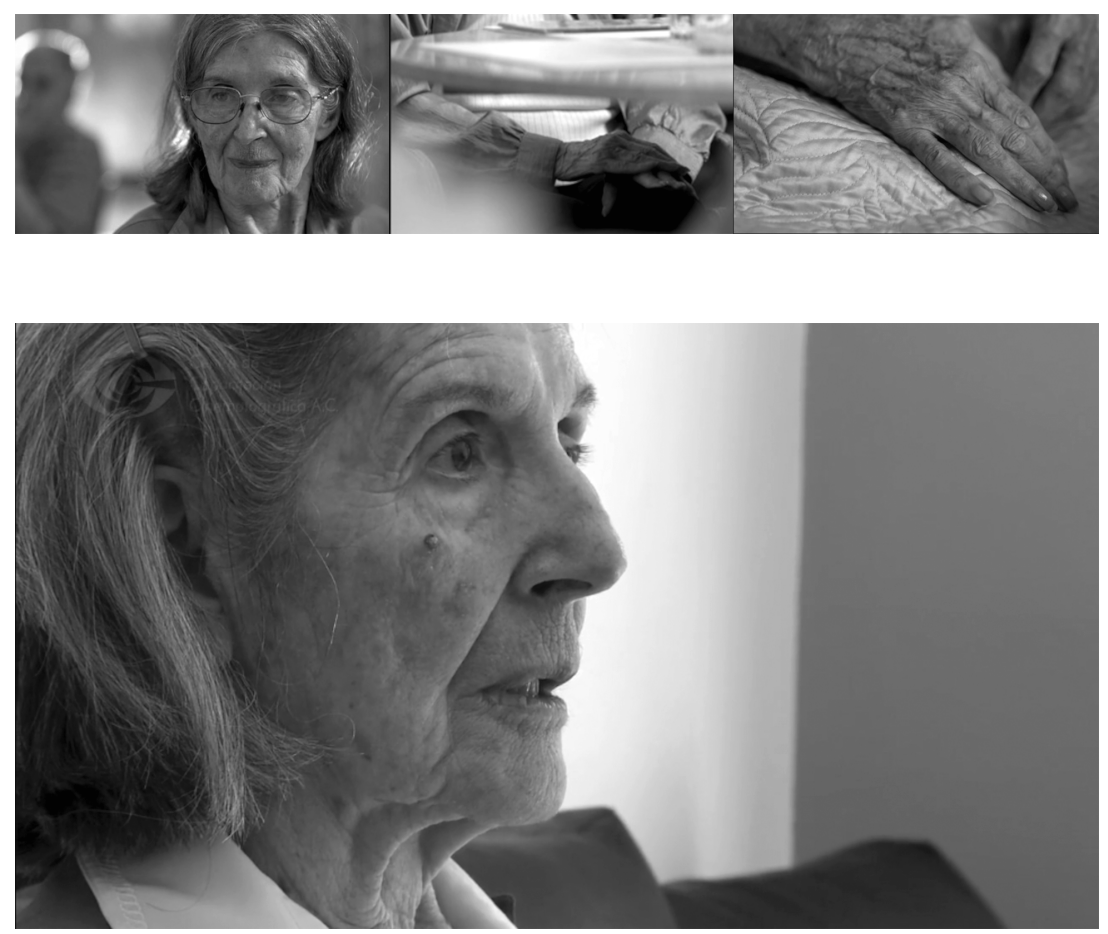

Figures 5.1 and 5.2 Tiempo suspendido. Natalia Bruschtein (dir.).

family members, the conversations with her granddaughter and, above all, the progression of her disease.

The sequence that shows for the first time both grandmother and granddaughter on screen together, sitting and looking at pictures, is composed of frames in which pictures occupy the full screen, close-up shots of Bonaparte and Bruschtein looking at photographs and talking about them, and medium shots that frame both women sitting at a table full of photographs. Each of these types of shots has a specific communicative function: photographs filling the screen allow the two women to talk about a past which no longer exists (Barthes) but also make viewers feel that they are looking at the picture as if they were part of the film; close-up shots that alternate photographs and the two people looking at them communicate at the level of emotions, immersing viewers into the action taking place and drawing them closer to both characters; and, finally, medium shots serve the purpose of pushing viewers back and out of the scene in order to emotionally distance them from what is about to happen. 
Bonaparte is constantly asked to name the people in the pictures shown to her. When Bonaparte tells her granddaughter that she does not remember their names, Bruschtein tells her the names of Bonaparte's children and discloses that three of them are dead. The revelation prompts Bonaparte to remember the death of her children, and her emotions are expressed through facial gestures that convey distress (see Figure 5.3).

Before analysing the viewer's position in this scene, it is important to offer the filmmaker's perspective on this specific moment, because she accepts that she too emotionally struggled with her grandmother's reaction:

She went through the same set of photos repeatedly. Whenever she got to that photo (which was an image that accompanied me all my childhood because I was at my grandmother's house and was with her through all the years of searching and struggling) sometimes she recognised them [her children] and sometimes she did not. The moment that remained in the film is a moment that for me was also very powerful, because at that moment I was not the director but the granddaughter feeling a lot of pain because she did not remember her own children, my father.

(Medina, "Interview with Natalia Bruschtein")

Despite Bruschtein's acknowledgement of her emotional involvement, the sequence does not show her reaction, only Bonaparte's. Leaving herself off-camera, Bruschtein stresses the split that the filmmaker makes on screen as filmmaker and granddaughter. Viewers are left to watch

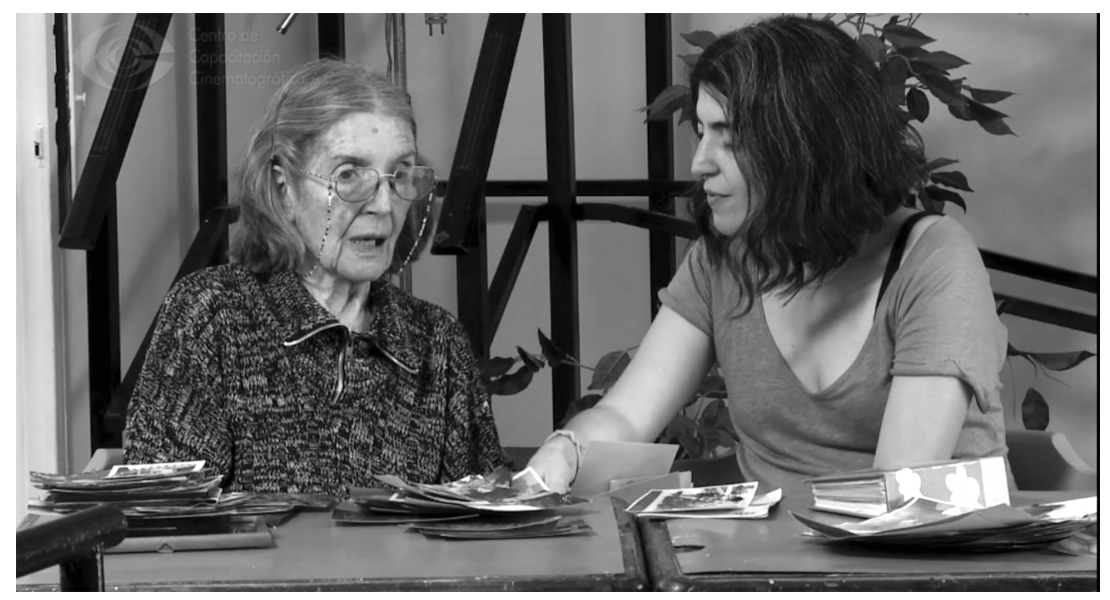

Figure 5.3 Tiempo suspendido. Natalia Bruschtein (dir.). 


\section{Raquel Medina}

Bonaparte's traumatic reaction through a medium shot placing them as witnesses who observe the moment when a traumatic event is recalled but where they cannot intervene (Sontag). Regardless of whether her consent was obtained or whether the filmmaker's motivation was disclosed, Bonaparte is pressed to involuntarily re-experience a traumatic event. In consequence, the subject (private Bonaparte) is transformed into the object of knowledge for both the filmmaker and the viewer: the public figure of Bonaparte as a well-known activist and, now, a person forgetting the past. The emphasis on this transformation may help to erase any traces of the emotional identification that Bonaparte's reaction may have initially triggered in the viewer.

Bruschtein's familial bond with her grandmother created the intimacy and familiarity necessary to facilitate filming with a person with dementia, as did Bonaparte's previous experience in front of the camera: "My grandmother never had problems with being in front of the camera; she was interviewed many times since the disappearance of her children.... So, she was not uncomfortable with our presence, on the contrary. Shooting with her was simple; we respected her times and moments" (Medina, "Interview with Natalia Bruschtein"). Although the filmmaker's words emphasise the duality of Bonaparte as both a public figure and a private citizen, it is Bonaparte's role as a public figure that takes centre stage, thus displacing/hiding Bonaparte's private self until the moment she no longer remembers her public past.

These recurrent encounters between Bonaparte and the filmmaker generate in the viewers a series of emotions and feelings that can range from pity and sadness to annoyance and shock at the filmmaker's insistent pressure to make Bonaparte remember a traumatic event. Karen Gerders elaborates on the differences between pity - condescendingly feeling sorry for someone; pitying someone in care settings might result in infantilising or shaming - and empathy - an initial unconscious and automatic affective reaction of the observer to another's emotional state, a reaction which may lead to a compassionate action. The encounters between Bonaparte and Bruschtein can certainly induce emotions and feelings that generate empathy towards Bonaparte in viewers, especially when they feel the suffering of private Bonaparte triggered by remembering the death of her loved ones. However, even if it was never the filmmaker's intention, the film also reinforces Bonaparte's physical and cognitive impairment as decline and therefore tends to evoke an emotion that may be closer to pity than to empathy. As a result, viewers cannot take any compassionate action; they can only remain mere witnesses of her suffering and therefore keep themselves emotionally distanced after an initial affective and empathic reaction.

The duality of Bonaparte's identity as a public figure and a private citizen in the film also affects the viewer's relation to her on screen. The dominance of her public figure throughout the film ${ }^{4}$ relegates the private 
citizen Laura Bonaparte to the background for most of it, thus presenting her as the object of a historical narrative or even as a historical figure. This dominance is reversed when her dementia rapidly progresses near the end of the film, with more scenes of Bonaparte's life at the nursing home shown on screen. Her initial humorous interactions with nurses have evolved into anger issues and a refusal to be fed or washed, all symptoms of dementia. This focus on the symptoms and deficits of the private Bonaparte is visualised through close-ups that concentrate on her wrinkled and thin hands and her unwashed hair; a focus that strengthens the "before/now" binary and may produce in the viewer the emotion of fear about the effects of dementia. These images create a great contrast with those documents shown early on that aim to provoke admiration for the public figure and, by contrast, lead viewers to feel pity for today's Laura Bonaparte. The viewer is constantly presented with TV segments and public speeches by an articulate Bonaparte that highlight the contrast with the forgetful and frail Bonaparte of the present, thus accentuating the decline narrative and the objectification of Bonaparte. The viewers may care about Laura Bonaparte's suffering in the past (the loss of her loved ones) and may care about her present frailty but cannot identify with her in ways that are meaningful for their own real-life experiences of care.

\section{El Señor Liberto y los pequeños placeres}

An opposite viewing experience and mode of representation are offered by Ana Serret in El Señor Liberto. Here Serret introduces what it means to live with Alzheimer's disease by highlighting the subjectivity and identity of the person living with the disease, as well as the possibility of affective communication through non-verbal language. In the same way, and by underscoring the artistic form and its means of production, the film suggests that aesthetic expression can reflect the experience of living with Alzheimer's.

The film documents the present of Liberto Serret, a retired engineer, widower and father of two daughters, who is in the final stages of Alzheimer's disease. He is not able to speak or walk and only moves his hands when music is played or in other limited circumstances. His daughter Ana, a filmmaker, moved with her two boys and her husband to Liberto's house after he was diagnosed and hired a Paraguayan carer, Luz, a year later. The documentary shows how the small pleasures Liberto had in the past have remained in the present: he loved and loves classical music, photography, reading, drawing, kissing, coffee and cakes.

In an interview, Serret acknowledges that she did not ask for Liberto's consent because at the beginning of the shooting sessions she had not planned to produce a film but just to create a testimony about the special relationship between Luz and her father (Medina, "Interview with Ana 


\section{Raquel Medina}

Serret"). That is, Serret's initial idea was to record the reciprocal caring relationship between the caregiver and the person cared for and to keep these recordings unpublished. In addition, Serret comments that the close relationship she had with her father had allowed them to maintain important conversations about moving to live with him and his opposition to being placed in a nursing home as he got older. She also relates that her father supported her artistic career and was always very keen on visual artistic expressions, as his home-made movies prove. Nevertheless, consent was not requested at any point, thus raising the issue of Liberto's vulnerability to the gaze of his filmmaker daughter and to the viewers of the film. However, it can be argued, as the analysis that follows aims to show, that all the tools of the film production, such as camera, editing, light and sound, are employed to highlight Liberto's ability to communicate and to support his ongoing personhood despite his cognitive impairment.

Dementia studies underlines the need to overcome the Cartesian duality and, in order to do so, some scholars employ Maurice Merleau-Ponty's philosophy of corporeality and of the lived body. For Merleau-Ponty, there is a relationship between the body and the outside world, and therefore sensory experience and thought are entwined: thought is the product of the interaction between the body and the world it inhabits. Therefore, the sensory perception of the body, according to him, allows us to communicate with the Other. Eric Matthews indicates that aspects of identity are sedimented in the body's habits and consequently persist even in the presence of severe cognitive impairment. Also drawing on Bourdieu's habitus, Pia Kontos and Wendy Martin consider the body as a place where discourse is inscribed and where subjectivity is constituted (290). They underline how gesture communicates more than verbal expression because it reveals the social and cultural movements that have developed into habits. Gestures are derived from the interiorisation of the sociocultural environment and thus define the subject's identity. Dressing, movements of the different parts of the body, the way of sitting down, for instance, are all features derived from socialisation. Consequently, individuality or identity can be found in these gestures, meaning that memory in the body, identity and social relations are interconnected. Moreover, all the elements attached to the body, such as clothing, makeup and food preferences, should be considered to constitute a type of communication that takes place through the body.

In El Señor Liberto, the subjective experience of the person with dementia shows the centrality that the body and its gestural communication acquire. The director's unequivocal intention is to place the experience and identity of the person with dementia at the centre of the film. Liberto's perspective is offered to the viewers through a narrative organised using a subjective camera, editing and diegetic sound. The narrative is articulated through long sequences captured by a fixed camera that 
on multiple occasions offers viewers extreme close-up shots of bodies or body parts that are in movement. Additionally, these sequences alternate with fragments of $8 \mathrm{~mm}$ home movies, photographs, and objects that are accompanied by a diegetic sound that captures the daily life of Liberto's family: conversations, ordinary noises, and music. By using all these elements, communication is threaded through the senses to stress the normalcy of the life with dementia that is observed on screen. In other words, Liberto is part of a whole that does not isolate him, that does not point him out as different or abject but that incorporates him into the daily life of the family. The supposed deficits and symptoms are indistinct and perceived within the parameters of normalcy through the embodiment of communication.

Sight, which is central to cinematographic representation, is also central to this film as a medium that expresses, both in form and on a semantic level, Liberto's identity and subjectivity. In this sense, the camera itself has a structural role, as Serret states:

I wanted to film from the perspective of my father, not to film my father. I wanted to keep his personality over the disease. That is why it is filmed using backlighting. I did not want to show his face for several reasons: to maintain his dignity and not focus on the deterioration but on the person himself. That is why we do not see him when Luz bathes him or walks [him] down the corridor. We always see him against a window. It was his place at the table, but I placed the camera to encourage backlighting. If he was communicating with his hands now, why shoot his face? It did not make sense. I just wanted to get inside his head and film from there.

(Medina, "Interview with Ana Serret")

To convey the perspective of her father, Serret uses a fixed camera that never moves, which allows the filmmaker firstly to document the family's daily routine and secondly to make the camera the eyes of the viewer by creating the illusion that the viewer is part of the film as another member of the family, sharing every moment of their daily life. Finally, the camera recreates Liberto's subjectivity by focussing on still and moving images from the $8 \mathrm{~mm}$ home movies that replace his memories about past events. Through the fixed lens, the viewers can perceive what is happening as if they were in a still body like Liberto's and are placed within Liberto's subjectivity, enabling them to think, feel and see as Liberto does.

The first sequences of the film already reveal Serret's intention to offer a visualisation of Liberto's subjectivity. On a black screen, Liberto's origins are written down: date and place of birth, his name and the opposition of the priest to that name (the name means "freedman"). This is followed by a home movie in which Liberto, now a mature man, is seen being filmed by his wife, to whom he talks. The transition between these two 


\section{Raquel Medina}

sequences is made by a jump cut to a black screen that lasts for some seconds. After the title, there is a shot of a window through which the branches of a weeping willow can be seen. This shot lasts 37 seconds, and the background sound is of someone walking around and then moving a chair; finally, the silhouette of a woman's head appears, who while sitting says "let's eat." Another jump cut leads to a close-up of a hand holding a spoon, a bowl, a mortar, a glass and a water jug. This woman's hand is feeding someone, of whom all we see is a napkin on his chest. The 46-second shot lacks sound and the light outside contrasts with the darkness inside the house. With another jump cut, the film moves to a group shot in which we see a dining room with a window in the background and two figures: the figure of an old man with white hair just in front of the window and a woman sitting next to him. The woman stands up, and the old man is left alone in the dining room. The backlight prevents us from seeing the face of this almost motionless man, whose only visible feature is his white hair. The sound in the background is a running tap, while the woman returns to the dining room and talks to another man. The shot lasts 42 seconds. Another jump cut leads to an extreme close up of a mortar in which the woman seems to be crushing medication; similarly, in this shot, we see the woman's hands and the white-haired man's hand on the table. The shot ends after 18 seconds, with a jump cut to a black screen on which the following text is written: " 7 years ago my father was diagnosed with Alzheimer's. He could no longer live alone, so my family and I went to live with him. A year later, we hired Luz to take care of him." With this text, the film has introduced its topic and main purpose: making the viewer perceive and share Liberto's subjectivity and the care he receives from all members of the household.

Liberto's subjectivity is also recreated through the repetition of the structure of long sequences of both present filmed images and past home movies. But as the documentary progresses, the $8 \mathrm{~mm}$ images, somewhat spoiled by the passage of time, take up more time in the film, thus making it increasingly evident that we are witnessing a recreation of Liberto's memories. The moments of confusion in Liberto's mind are also recreated through the superimposition of images. Barbara Zecchi argues that the materiality of film can be employed to blur the boundaries between one's past and present: memories that belong to one's past are evoked and incorporated through grainy texture, blurred images and extreme closeups. This is exactly what Serret does to present Liberto's memory: she uses old home movies and pictures to visually recreate Liberto's memories. Just like Liberto's memories, films and pictures also age with time, thus experiencing discolouration and acquiring a grainy texture.

Another two techniques that stand out to emphasise the permanence of Liberto's self are the constant link made between elements of the present and those of the past and the continuity of common aspects through the different generations of the family. These common aspects have an impact 
on the durability of experiences and emotions, which survive in interpersonal relationships and facilitate reciprocity. Drawing, reading, playing and listening to music, kissing and caressing are all activities shared at some point in life by all members of the household. As the home movies show, Liberto was a great drawer and sculptor and an avid reader, pleasures that are enjoyed by both his children and grandchildren. In fact, all are bodily actions filled with emotions that have passed from generation to generation thus validating that habitus remains in the body - hearing, touch, taste and smell - even when cognitive impairment is present.

The little pleasures of Liberto - eating cakes, drinking coffee (see Figure 5.4), listening to music and, above all, talking with his hands - are all linked to the four senses, which seem to remain intact despite the progression of the disease. He actively responds to music (hearing), caressing and kissing (touch) and to eating cake and drinking coffee (taste and smell). The diegetic sound of the film offers the spectator the possibility of perceiving sounds in the same way as any of the other inhabitants of that house and, especially, in the way that Liberto does. His pleasure in music is central to the affective communication depicted. His body's unconscious reaction to classical music is revealed through his bodily reactions, such as his ability to keep the rhythm with his hands or the caressing of his daughter's arm. The sense of smell is evoked in the documentary through the home movies and images such as those of flowers, mountains, the sea or coffee. Memories, then, remain and are experienced in the present by and in the body through the "memory of the senses" (Marks): sight, hearing, taste, smell and touch all play key roles in the film.

The senses are the vehicles that help to produce ethical responses to the person living with dementia in the viewer. They do so through the nonconscious and pre-personal quality of affect, as the filmmaker herself states

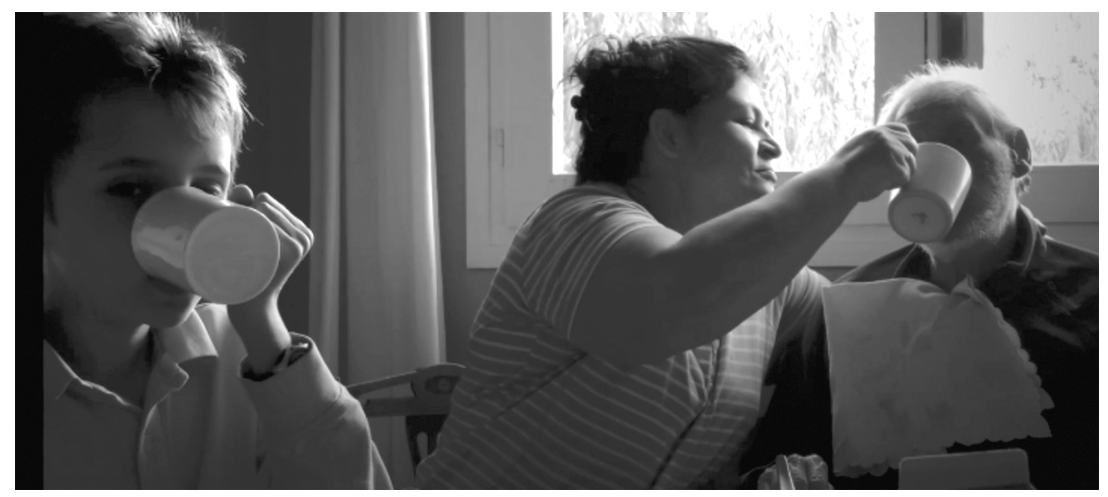

Figure 5.4 El señor Liberto y los pequeños placeres. Ana Serret (dir.). 


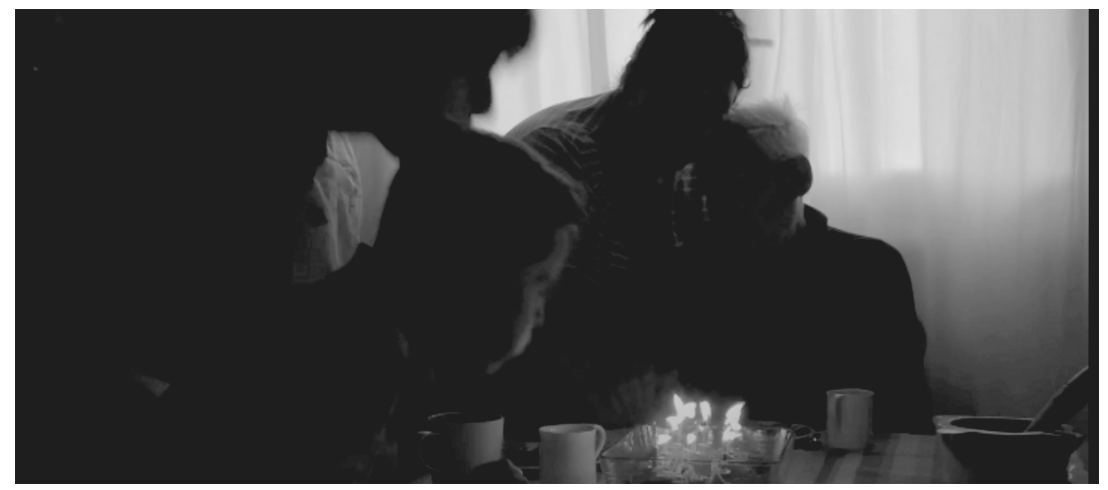

Figure 5.5 El señor Liberto y los pequeños placeres. Ana Serret (dir.).

(Serret). The camera leads the viewer to share and experience the same affects by creating "affective atmospheres" (Brennan) that generate understanding and empathy. Therefore, viewers cannot care for Liberto, but the film can make them feel as if they were part of the caring process. In these affective atmospheres, binaries such as able/disabled, body/mind and self/other are removed and replaced by sameness and continuity (see Figure 5.5).

Generating empathy in this way, the filmmaker practises an ethics of care, cutting across the limits of the film as an object to communicate with the viewer. Serret's film seems to reverse the socially and culturally constructed negative emotional reactions and feelings about people with dementia by making the viewer experience the subjectivity of the person. As viewers, we hear, see, touch, smell and taste with and through Liberto, and we perceive his nonconscious reactions. Because these types of affects are shown, emotions and feelings of empathetic caring about and for Liberto take centre stage, and the distance between the object (the film) and the subject (the viewer) seems reduced. The viewer gazes at Liberto and gazes at the world through Liberto, which ultimately draws the viewer closer to Liberto and his experience. Moreover, the viewer is made part of the household, sharing with other members their daily routine of caring for and about him. This transforms the public feature of the film into a private experience in which encounters between Liberto and the viewers are enabled, and dignified practices of care are supported.

Caring practices take place in this film within Liberto's home. Luz, the hired caregiver, becomes not only part of the family but also the most important pillar in the care Liberto receives. As Serret explains in the interview, Luz and Liberto became one, a unity that was based on trust:

He had never wanted a woman to take care of him, out of embarrassment. But Luz treated him with a lot of respect and dearly cared 
about him due to the trust gained in sharing with him her life and talking to him.... So, when my father, after some few years, little by little stopped talking, the two of them knew each other very well. My father felt safe with her and did everything she asked.

(Medina, "Interview with Ana Serret")

The sense of feeling safe clearly underlines two important issues: first, Liberto's acknowledgment and acceptance of his vulnerability and reliance on another person; and second, that feeling safe is strongly linked to trust. Dunn and Schweitzer define trust as "the willingness to accept vulnerability based upon positive expectations about another's behavior" (736). Furthermore, in the case of Liberto, the vulnerability of the person living with dementia is managed by the caring relationship adopted by Luz. Even when Liberto's cognition has deteriorated, Luz continues to communicate with Liberto by treating him as she did before in terms of identity and care. She talks to him in the same way as when he was still able to verbally respond to her. Luz anticipates Liberto's possible reactions and communicates with him through his little pleasures. As the film proves, care based on trust is not only assisting with the physical care of the person but also providing affective and emotional care, which highlights the importance of maintaining the identity and selfhood of the person living with dementia. Affective and emotional care needs to be linked to empathy: the emotion caused by the understanding of the suffering of another person. Therefore, empathy replaces pity and leaves the carer and the person cared for at the same level in the recognition of their own and mutual vulnerability.

\section{Conclusion}

Despite the fact that both films are characterised by a familial relationship between the film directors and the main protagonists, the comparison between these two documentary films has shown two different, almost antithetical, ways of presenting people with dementia in front of the camera. The comparative analysis of both films has shown that the harm to subjects that the filmic interaction can cause can be mitigated by the role assigned to the person living with dementia in front of the camera and the concept of care presented. Tiempo suspendido focusses on the dual nature of Laura Bonaparte as a private citizen and as a public figure and by doing so it patently emphasises the role of the public figure and relegates the private one to the otherness that ageing and dementia entail. It can be argued that Tiempo suspendido is rooted in the Cartesian notion of the mind/body: once cognition is impaired, identity is gone, and only the body remains. In contrast, El Señor Liberto shows that Liberto's identity has remained intact by focussing on his subjectivity and his lived experience instead of deficits. 
These opposite approaches to the object/subject of knowledge have an overarching effect in terms of the ethics of representation and the ethics of care. Each film presents a different concept of care ethics: while Tiempo suspendido focusses on the paradoxical quality of memory and its meaning within the political context of Argentina, El Señor Liberto documents embodied memory and how the individual is part of different networks of relationships (Koggel) that define both them and their counterparts. Regardless of memory loss, Serret's film tells us that the memory of the senses is what we all share, and therefore we can communicate through them when language is gone. By showing on screen how a person living with dementia is cared for, both films foreground key aspects of the experiences of dementia and care. For instance, in Tiempo suspendido, Laura's physical and mental deterioration becomes central, and it is stressed as the film progresses by increasingly introducing scenes where her daily routine at the nursing home is shown. In Serret's film, three generations of the same family live together and, although they hire a caregiver to carry out daily care for Liberto, they all participate in the same activities and daily routines that incorporate the person living with dementia. It could be said that Liberto is placed at the same level as any other family member, therefore simultaneously receiving care and being cared about.

Finally, the role that the camera plays and where it positions the viewer are essential for the ultimate understanding of the meaning of dementia at both individual and social levels and consequently can have a crucial part in shaping the social understanding of what living with dementia involves. Tiempo suspendido maintains the distance between the cinematographic object (those on film) and the viewers, who witness the harmful moment in which Bonaparte is pushed to remember the death of her children. Despite the possibility of initially generating a very brief and momentarily empathic response, the objective gaze does not allow any further affective engagement with the person living with dementia, beyond pity. From this point onwards, the viewers gazing at Bonaparte are likely to experience emotions of fear and feelings of disgust as a consequence of the film's emphasis on Bonaparte's decline. In contrast, El Señor Liberto deploys a cinematic language based on haptic visuality or visuality of the senses. Through this hapticity, the subjective camera allows the viewer to experience what Liberto feels, thus facilitating understanding and communication. This communication leads to a practice of care that could be considered reciprocal and interpersonal and goes beyond the filmic object per se, because the viewer becomes a participant in the network of relationships of which Liberto is part. In this film, Serret employs an original cinematic language to empathically connect with the person living with dementia through emotions and affects and to present embodied memories that are shared and lived with the viewer. This way, the notion that one affects others, one is affected 
by others and we feel with others becomes in this film the pillar of its ethics of care.

\section{Notes}

1. Small parts of the chapter have been adapted from two published articles: Medina (2020) and Medina (in press).

2. "Affective turn" scholars either do not differentiate between affect, emotions and feelings (Ahmed; Brennan; Ngai) or consider affect as pre-personal, nonconscious and autonomous from emotions (Massumi, Parables, Politics; Ross).

3. See Susan M. Behuniak; Hannah Zeilig; Aagje Swinnen and Mark Schweda.

4. The past of the public figure of Bonaparte is reconstructed through photographs, speeches, newspaper articles, interviews, TV programs and so on. The private past of Bonaparte is reconstructed through the questions asked of her and personal photographs. The documents pertaining to Bonaparte's public persona are all available at Argentina's National Library Archives; consequently, none of the questions she is asked aim to uncover an unknown truth since all facts are already known.

\section{Works Cited}

Ahmed, Sara. The Cultural Politics of Emotion. Edinburgh UP, 2004.

Behuniak, Susan M. "The Living Dead? The Construction of People with Alzheimer's Disease as Zombies." Ageing and Society, vol. 31, no. 1, 2011, pp. 70-92.

Braidotti, Rosi. Nomadic Subjects: Embodiment and Sexual Difference in Contemporary Feminist Theory. Columbia UP, 2011.

Brennan, Teresa. The Transmission of Affect. Cornel UP, 2004.

Buchart, Garnet C. "On Ethics and Documentary: A Real and Actual Truth." Communication Theory, vol. 16, no. 4, 2006, pp. 427-52.

Butler, Judith. "Torture and the Ethics of Photography." Environment and Planning D: Society and Space, vol. 25, no. 6, 2007, pp. 951-66.

Couser, G. Thomas. Vulnerable Subjects: Ethics and Life Writing. Cornell UP, 2004.

DeFalco, Amelia. Imagining Care: Responsibility, Dependency, and Canadian Literature. U of Toronto P, 2016.

Dubois, Philippe. "Photography Mise-En-Film. Autobiographical (Hi)stories and Psychic Apparatuses." Fugitive Images. From Photography to Video. Edited by Patrice Petro. Indiana UP, 1995, pp. 152-72.

Dunn, Jennifer R., and Maurice E. Schweitzer. "Feeling and Believing: The Influence of Emotion on Trust." Journal of Personality and Social Psychology, vol. 88, no. 5, 2005, pp. 736-48.

Gilligan, Carol. In a Different Voice. Harvard UP, 1982.

Gorton, Kristyn. "Theorizing Emotion and Affect: Feminist Engagements." Feminist Theory, vol. 8, no. 3, 2007, pp. 333-48.

Katz, John Stuart, and Judith Katz. "Ethics and the Perception of Ethics in Autobiographical Film." Image Ethics: The Moral Rights of Subjects in Photographs, Film, and Television. Edited by Larry Gross et al. Oxford UP, 1988, pp. 119-30.

Koggel, Christine M. Perspectives on Equality: Constructing a Relational Theory. Rowman \& Littlefield, 1998. 


\section{Raquel Medina}

Kontos, Pia, and Wendy Martin. "Embodiment and Dementia: Exploring Critical Narratives of Selfhood, Surveillance, and Dementia Care.” Dementia, vol. 12, no. 3, 2013, pp. 288-302.

Landsberg, Alison. Prosthetic Memory: The Transformation of American Remembrance in the Age of Mass Culture. Columbia UP, 2004.

Marks, Laura. The Skin of the Film: Intercultural Cinema, Embodiment, and the Senses. Duke UP, 2000.

Massumi, Brian. Parables for the Virtual: Movement, Affect, Sensation. Duke UP, 2002.

- Politics of Affect. Polity Press, 2015.

Matthews, Eric. "Dementia and the Identity of the Person." Dementia: Mind, Meaning and the Person. Edited by Julian C. Hughes et al. Oxford UP, 2006, pp. 163-77.

Medina, Raquel. Cinematographic Representations of Alzheimer's Disease. Palgrave Macmillan, 2018.

—. "Interview with Natalia Bruschtein." Gynocine Project, 2019, www. gynocine.com/interview-natalia-bruschtein.

. "El poder de los sentidos en El señor Liberto y los pequeños placeres de Ana Serret (2017): representaciones de la subjetividad e identidad en las personas con alzhéimer," Bulletin of Contemporary Hispanic Studies, vol. 2, no. 1, 2020, pp. 51-68.

—. "Interview with Ana Serret." Unpublished, 2020.

and Barbara Zecchi. "Technologies of Age: The Intersection of Feminist

Film Theory and Aging Studies." Revista de Investigaciones Feministas, vol. 11, no. 2, 2020, pp. 251-62.

Merleau-Ponty, Maurice. Phenomenology of Perception. Translated by Colin Smith. Routledge and Kegan Paul, 1962.

Ngai, Sianne. Ugly Feelings. Harvard UP, 2007.

Nichols, Bill. Introduction to Documentary. Indiana UP, 2001.

Noddings, Nel. Caring: A Feminine Approach to Ethics. U of California P, 1984.

Ross, Andrew A. G. "Coming in From the Cold: Constructivism and Emotions." European Journal of International Relations, vol. 12, no. 2, 2006, pp. 197-222.

Serret, Ana. "El señor Liberto y los pequeños placeres, 'Notas de la directora'." elsenorlibertoylospequenosplaceres.wordpress.com/notas-de-la-directora/. Accessed 2 Apr. 2020.

Sontag, Susan. Regarding the Pain of Others. Picador, 2003.

Swinnen, Aagje, and Mark Schweda, editors. Popularizing Dementia: Public Expressions and Representations of Forgetfulness. Transcript, 2015.

Vanacker, Bastiaan, and John Breslin. "Ethics of Care: More Than Just Another Tool to Bash the Media?" Journal of Mass Media Ethics, vol. 21. no. 2-3, 2006, pp. 196-214.

Zecchi, Barbara. "Gendered Aging and Sexuality in Audiovisual Culture." Encyclopedia of Gerontology and Population Aging. Edited by Danan Gu and Matthew E. Dupre. Springer, 2019, https://doi.org/10.1007/978-3-319-69892.

Zeilig, Hannah. "Dementia as a Cultural Metaphor." The Gerontologist, vol. 54, no. 2, 2014, pp. 258-67. 


\section{Filmography}

El señor Liberto y los pequeños placeres. Directed by Ana Serret. Rojo Films, 2018.

Tiempo suspendido. Directed by Natalia Bruschtein. Centro de Capacitación Cinematográfica, 2015. 